\title{
Does the trematode Centrocestus formosanus affect the locomotory activity of the mollusc Melanoides tuberculatus?
}

\author{
Everton Gustavo Nunes dos Santos, Viviane da Silva Costa and Cláudia Portes Santos*
}

\begin{abstract}
Background: Melanoides tuberculatus (Müller, 1774) (Thiaridae), an introduced gastropod mollusc with a wide geographical distribution in the Neotropics, is the intermediate host of the trematode Centrocestus formosanus (Nishigori, 1924) (Heterophyidae). This parasite is considered to be pathogenic to humans. The aim of the present work was to evaluate the locomotory activity of uninfected $M$. tuberculatus compared with those naturally infected with C. formosanus.

Findings: The locomotory activity of each mollusc was recorded using an image analysis biomonitoring system, Videomex-V ${ }^{\circledR}$, to evaluate and quantify the parameters of 'Stereotypic' and 'Resting time'. The Generalized Estimating Equation analysis of locomotory activity of M. tuberculatus infected with C. formosanus revealed significant differences compared with uninfected molluscs for the parameters 'Stereotypic time' and 'Resting time' with a reduction of movement. The variations in the values of the monitoring intervals recorded showed a significant difference for the infected molluscs in the case of Stereotypic time, with an irregular locomotory activity pattern, as compared to that of uninfected molluscs. The analysis of the standard length of all molluscs did not exhibit any correlation with locomotory activity, showing that C. formosanus is able to alter the locomotory activity of its snail host regardless of the standard length.
\end{abstract}

Conclusions: The trematode C. formosanus affects the locomotory activity of the mollusc M. tuberculatus by reducing its movement and causing it to exhibit an irregular pattern of activity, both of which are independent of the snail's standard length.

Keywords: Behavioural changes, Movement, Locomotory activity, Trematoda, Mollusca, Brazil

\section{Findings}

\section{Background}

Parasitic infections can alter the physiology and behaviour of their hosts and in an ecological context, such changes can increase the exposure of the host to various predators [1]. For instance, parasites that use molluscs as intermediate hosts can, during the process of asexual reproduction, utilize the host's resources, causing an immediate effect on its physiology [2]. Accordingly, Levri et al. [3] showed that the intramolluscan stage of the trematode Microphallus sp. is able to alter the rate of both the movement in response to light and the vertical

\footnotetext{
* Correspondence: cpsantos@ioc.fiocruz.br

Laboratório de Avaliação e Promoção da Saúde Ambiental, Instituto Oswaldo Cruz, Fundação Oswaldo Cruz, Av. Brasil, 4.365, Manguinhos, Rio de Janeiro
} 21040-360, Brazil movement of the mollusc Potamopyrgus antipodarum (Gray, 1853), possibly enhancing its chances of transmission to the next host and decreasing the probability of the latter being captured by predators.

Aquatic environments offer ideal conditions for the development and maintenance of parasite life cycles, mainly because the water viscosity facilitates the dispersal of eggs and free-living stages, enabling the maintenance of complex parasite life cycles [4]. In the area of Rio de Janeiro, Brazil, the life cycles of digenean species have been elucidated in the ecosystem of the Rodrigo de Freitas lagoon [5-8] and maintained in our laboratory, enabling us to compare the swimming behaviour of an intermediate fish host before and after a digenean infection using an image analysis biomonitoring system [9]. Although the avian and fish fauna of the lagoon are well known, there

\section{Biomed Central}

(c) 2013 dos Santos et al.; licensee BioMed Central Ltd. This is an Open Access article distributed under the terms of the Creative Commons Attribution License (http://creativecommons.org/licenses/by/2.0), which permits unrestricted use, distribution, and reproduction in any medium, provided the original work is properly cited. 
are few studies on molluscs in this area [6], among which is the 'red-rim melania' Melanoides tuberculatus (Müller, 1774) (Thiaridae), an introduced gastropod snail which now has a wide geographical distribution throughout the Neotropics [10].

Melanoides tuberculatus is reported to be a well-adapted intermediate host for members of at least 16 trematode families, including 25 genera and 37 species [11]. Among these, the trematode Centrocestus formosanus (Nishigori 1924), parasitic as an adult in mammals and birds, is considered to be pathogenic to humans; it is also able to cause the death of small fish, as a result of a massive infection of metacercariae [12-14]. Although it's negative impact on fish intermediate hosts and humans is well known [13,14], the effect of the parasitism of C. formosanus on M. tuberculatus requires further investigation.

The aim of this study was to evaluate whether $C$. formosanus can alter the locomotory activity of $M$. tuberculatus by comparing individual molluscs, which were naturally parasitized with uninfected ones using an image analysis biomonitoring system.

\section{Methods \\ Collection and analysis of M. tuberculatus}

A total of 65 specimens of $M$. tuberculatus (15-25 mm standard length) were randomly collected at a single station on the edge of the Rodrigo de Freitas Lagoon, Rio de Janeiro, Brazil ( $\left.22^{\circ} 97^{\prime} 00^{\prime} \mathrm{S}, 43^{\circ} 21^{\prime} 65^{\prime \prime} \mathrm{W}\right)$. They were maintained alive in laboratory aquaria filled with filtered lagoon water and fed with commercial fish food flakes. During a period of 3 months, the molluscs were examined for cercariae once per week. Individual snails were isolated in $20 \mathrm{~mL}$ vessels containing filtered lagoon water, exposed to artificial light for 4 hours and examined under a stereomicroscope. All shed cercariae were identified as C. formosanus following Scholz and SalgadoMaldonado (2000). Thus, the molluscs were separated into two groups: uninfected and infected. After the experiments, all molluscs were examined to confirm the presence or absence of parasites.

\section{Image analysis biomonitoring system}

The image analysis biomonitoring system (IABS) used in this study is that used by Magalhães et al. $[9,15]$. The IABS is composed of an illuminating cabin and a recording cabin made of acrylate and holding a fixed analogue video camera. The images were sent to a Videomex $\mathrm{V}^{\circledR}$ video tracking system (Columbus Instruments, Ohio, USA) and analyzed using the software Travelled Distance of Multiple Objects (TDMO). Data were sent to a computer and recorded in an Excel spreadsheet.

During the experiments, molluscs were placed individually in 8 holding boxes $(4 \times 4 \times 2 \mathrm{~cm}$ each $)$ made of opaque acrylate with $3 \mathrm{~mm}$ holes, which were kept inside an opaque glass aquarium of $30 \mathrm{~L}$ capacity $(35 \times 35 \times$ $25 \mathrm{~cm}$ ) filled with filtered water from the lagoon. Submerged water pumps maintained the water circulation under a controlled temperature of $21^{\circ} \mathrm{C}$.

Each experiment was performed during a $68 \mathrm{~min}$ period, with $20 \mathrm{~min}$ of acclimation and $48 \mathrm{~min}$ of monitoring analysis recorded at 48 intervals of 1 min each. All values of each interval of 'Stereotypic time' and 'Resting time' were tested simultaneously and used for statistical analysis. 'Stereotypic time' is the total number of seconds during the interval in which the mollusc performed some movement activity, whereas 'Resting time' is the total number of seconds during the interval spent without movement.

\section{Statistical analysis}

All statistical analyses were performed using the R statistical program (version 2.15.0) [16]. The Mann-Whitney test was used to evaluate the differences between the standard length of infected and uninfected molluscs. This nonparametric test was used due to the non-normal distribution of the samples.

For the behavioural experiments, we used the Generalized Estimating Equation (GEE) with the packages "geepack" and "yags" [17]. This test analyzed repeat measurements of the locomotory activity data ('Stereotypic time' and 'Resting time') of infected and uninfected molluscs, estimating the parameters of regression and variance in the dependent timings. In an attempt to verify a locomotory pattern in each of the groups (uninfected and infected molluscs), the differences between the values obtained in each recorded interval during the monitoring period were analyzed using GEE. In addition, also using GEE, we tested the influence of the standard length of infected and uninfected molluscs in relation to the 'Stereotypic time' and 'Resting time'.

The model was performed using each behavioural parameter as a variable response with a Gaussian error distribution, identity-link function and exchangeable correlation structure. A goodness-of-fit statistic, the quasi-likelihood information criterion (QIC), was used for evaluating the models [18]. The level of significance assumed for statistical tests was $5 \%$.

\section{Ethical considerations}

This research was licensed by the Brazilian Institute of Environment and Renewable Natural Resources (IBAMA no. 15898-1) and approved by the Animal Ethics Committee of the Oswaldo Cruz Foundation (CEUA-FIOCRUZ LW12/10), in accordance with the guidelines of the Brazilian College for Animal Experiments (COBEA). 


\section{Results}

The GEE analysis of the standard length of all 65 molluscs (15-25 mm, mean $18.55 \pm 1.9)$ did not exhibit any correlation with locomotory activity (Stereotypic time, coefficient estimation $=-0.48 \pm 1.11$, Wald statistic $_{1584}=0.19, P=$ 0.66 ; Resting time, coefficient estimation $=0.58 \pm 1.19$, Wald statistic $_{1584}=0.24, P=0.62$ ).

Of the molluscs analyzed, 30 did not shed cercariae and 35 shed cercariae of $C$. formosanus (only) daily. The uninfected molluscs measured 15-20mm $(18 \pm 1.3)$ in standard length and the infected ones were $15-25 \mathrm{~mm}(19 \pm 2.3)$. The Mann-Whitney $U$ test showed significant differences in standard length between the infected and uninfected molluscs $\left(W_{64}=1103, P<0.001\right)$.
The GEE analysis of locomotory activity revealed significant differences between infected and uninfected molluscs for the parameters 'Stereotypic time' (coefficient estimation $=10.50 \pm 4.07$, Wald statistic $3312=$ $6.66, P=0.009$, Figure 1a) and 'Resting time' (coefficient estimation $=-10.31 \pm 4.14$, Wald statistic $_{3312}=6.19, P=$ 0.01 , Figure 1b).

The GEE analysis between the values of the 48 monitoring intervals recorded during the monitoring period compared the locomotory pattern in each of the groups (uninfected and infected molluscs). The differences in the values for the uninfected molluscs, was not significant for the parameters Stereotypic time (coefficient estimation $=-0.04 \pm 0.08$, Wald statistic $3312=0.26, P=$

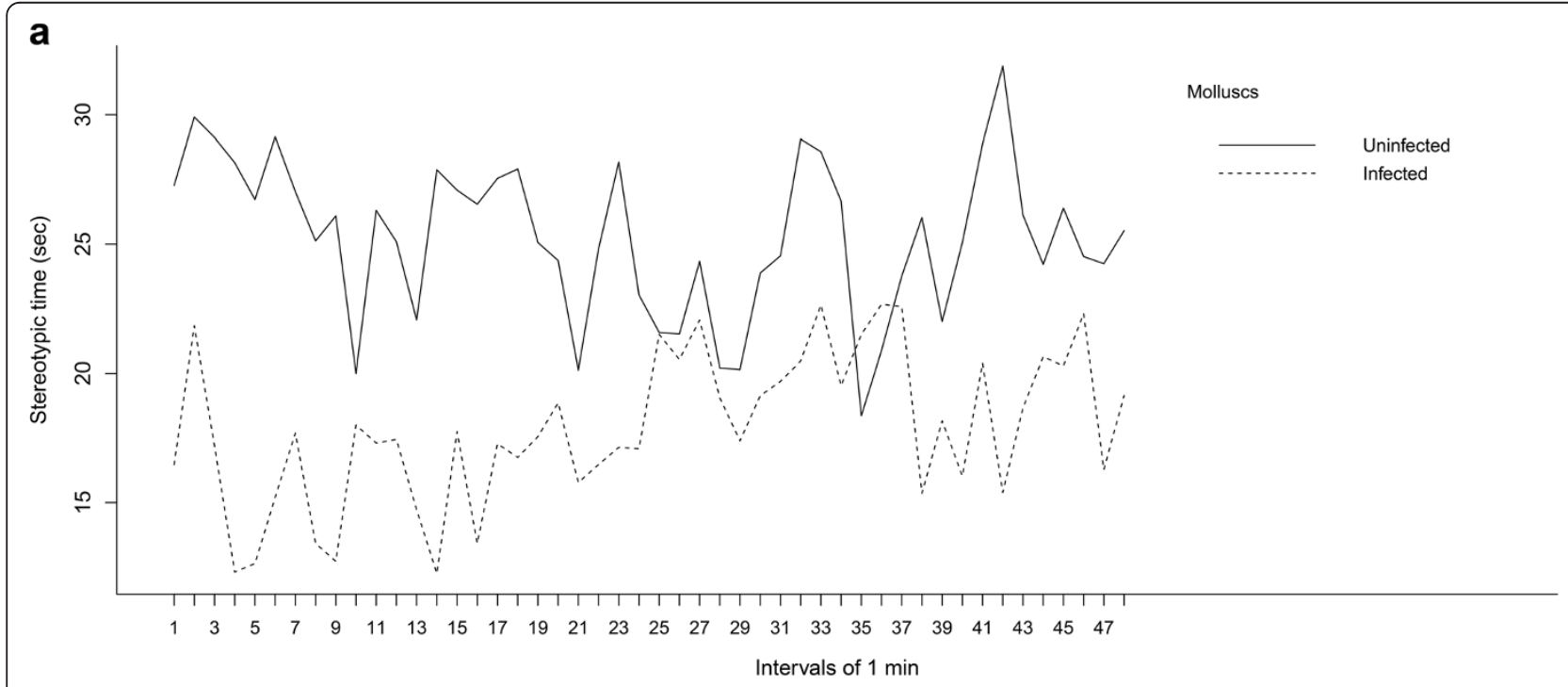

b

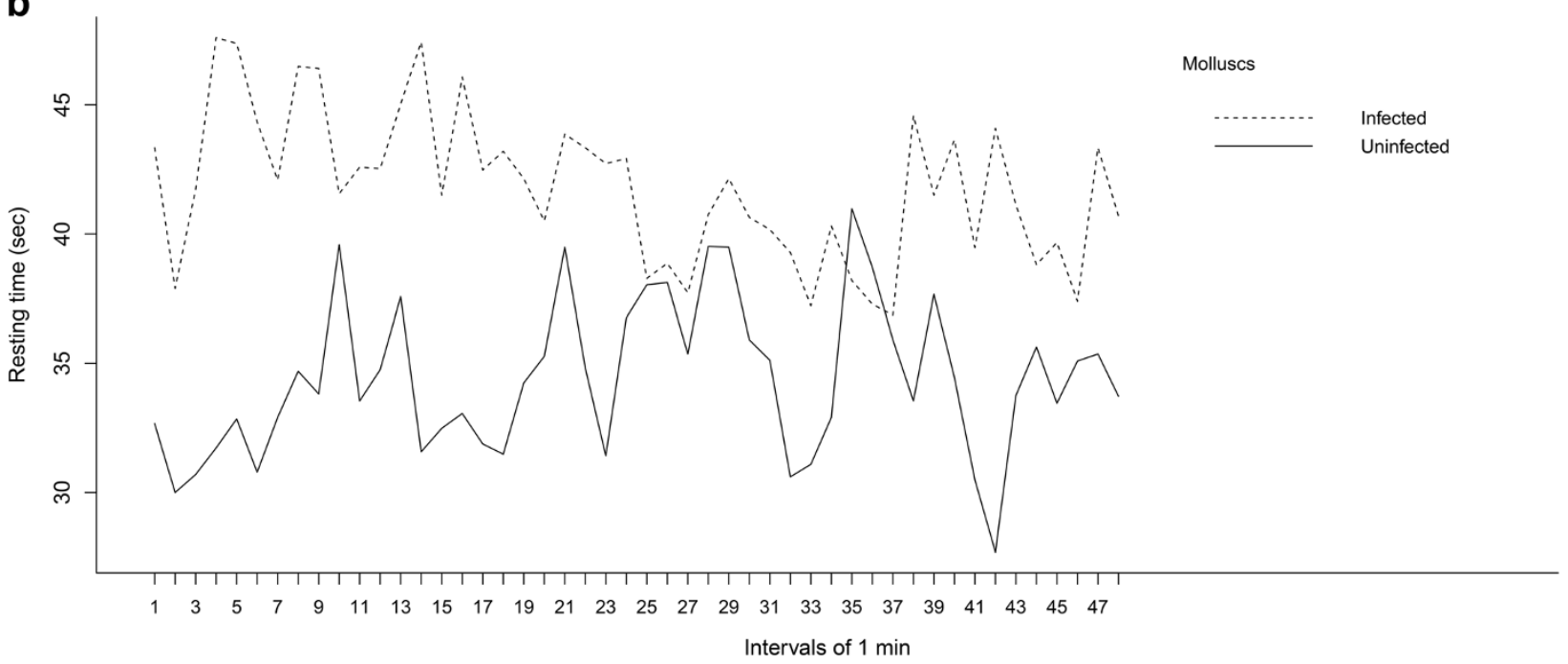

Figure 1 Monitoring analysis of Melanoides tuberculatus uninfected and naturally infected by Centrocestus formosanus. Comparative graphics showing significant differences between 48 intervals of 1 min of monitoring analysis of (a) Stereotypic time (seconds) and (b) Resting time (seconds) of Melanoides tuberculatus uninfected and naturally infected by Centrocestus formosanus. 
0.60 ) and Resting time (coefficient estimation $=0.04 \pm$ 0.89 , Wald statistic $3312=0.21, P=0.64$ ); this was thus considered a regular pattern. However, the same test for the infected molluscs showed a marginally significant difference for Resting time (coefficient estimation $=-0.10 \pm$ 0.05 , Wald statistic ${ }_{3312}=3.81, P=0.05$ ) and a significant difference in the case of Stereotypic time (coefficient estimation $=0.10 \pm 0.05$, Wald statistic $3312=3.91, P=0.04$ ); this was considered an irregular pattern.

\section{Discussion}

Host-parasite relationships are an intriguing subject as they involve, for example, competition for energy and nutrients involving complex physiological processes, as well as changes in the rate of growth and other metabolic variation [19-21].

Stress conditions are reported to occur due to metabolic changes in molluscan hosts caused by trematodes when the intramolluscan stages influence the mobilization of calcium between the shell and haemolymph during their larval development [21]. In addition, the accelerated metabolic rate of energy of the infected molluscs caused by the development of parasite larvae results in a negative imbalance due to the high consumption of nutrients [20-22]. Thus, a consequence of such effects can probably alter the behavioural pattern of the molluscan host.

The dimensions of the shells of molluscs may also be influenced by parasitism [23-25]. In our study, infected $M$. tuberculatus were significantly longer than the uninfected ones $(P<0.001)$. However, a comparison of the length of all molluscs with their locomotory activity showed no significant correlation. Nevertheless, when the locomotory activity of infected vs. uninfected hosts was compared, the former had a significantly reduced 'Stereotypic time' and an increased 'Resting time'. Although Miller \& Poulin [2] have reported that parasitized snails had larger dimensions of shells and were found to move a significantly shorter distance than uninfected snails, our survey shows that the parasite $C$. formosanus is able to alter the locomotory activity of $M$. tuberculatus irrespective of the snail's standard length.

The host-parasite association can be seen as a constant conflict between the needs of the parasite and those of the host for growth, reproduction and survival [26]. Consequently, it is possible that the parasite influences the behaviour of its hosts in ways that increase the probability of its transmission, as discussed by [27]. Melanoides tuberculatus infected with Centrocestus formosanus, in addition to a reduced movement, exhibited an irregular locomotory activity pattern, whereas uninfected snails had a regular pattern of locomotory activity during the biomonitoring period. A similar experiment by Santos et al. [9], using a Videomex $\mathrm{V}^{\circledR}$ system, assessed the locomotory activity of fish hosts in the same lagoon, and these authors suggested that a lethargic and less motile parasitized fish is more likely to be preyed upon by the definitive host. In the case of the less motile snail host, we consider that it is more likely to influence the life cycle of $C$. formosanus by concentrating the shedding of cercariae into a more restricted area.

\section{Conclusions}

The trematode Centrocestus formosanus affects the locomotory activity of the mollusc Melanoides tuberculatus by reducing its movement and causing it to exhibit an irregular pattern of activity, both of which are independent of the snail's standard length.

\section{Competing interests \\ The authors declare that they have no competing interests.}

\section{Authors' contributions}

CPS and EGNS conceived and designed the study. VSC performed the parasitological examinations. EGNS performed the tests and did the statistical analysis. CPS and EGNS wrote the paper. Supervisor of MSc: CPS. All authors read and approved the final version of the manuscript.

\section{Acknowledgements}

We are grateful to Dr David I Gibson of the Natural History Museum, London and Mr Rodolfo Cunha from the Oswaldo Cruz Institute for their valuable suggestions. Orlando Marins Filho provided the mollucan hosts.

\section{Financial support}

This study was funded by the Fundação Carlos Chagas Filho de Amparo à Pesquisa no Rio de Janeiro (FAPERJ- BIOTA 2012), Coordenação de Aperfeiçoamento de Pessoal de Nível Superior (PROCAD NF/2009 and Parasitologia Básica/2011) and PROEP CNPq/FIOCRUZ. This study is part of the master's thesis of the first author in the Programa de Pós-Graduação em Ciências Veterinárias, Universidade Federal Rural do Rio de Janeiro, Brazil.

Received: 28 January 2013 Accepted: 25 March 2013 Published: 10 April 2013

\section{References}

1. Kolluru GR, Green ZS, Vredevoe LK, Kuzma MR, Ramadan SN, Zosky MR: Parasite infection and sand coarseness increase sand crab (Emerita analoga) burrowing time. Behav Process 2011, 88:184-191.

2. Miller AA, Poulin R: Parasitism, movement, and distribution of the mollusc Diloma subrostrata (Trochidae) in a soft-sediment intertidal zone. Can J Zoolog 2001, 79:2029-2035

3. Levri EP, Lunnen SJ, Itle CT, Mosquea L, Kinkade BV, Martin TG, Delisser MA: Parasite-induced alteration of diurnal rhythms in a freshwater mollusc. J Parasitol 2007, 93:231-237.

4. Barber I, Poulin R: Interactions between fish, parasites and disease. In The Handbook of Fish and Fisheries P. J. B. Hart \& J. D. Reynolds). Oxford: Blackwell Science; 2002:359-389.

5. Simões SBE, Scholz T, Portes Santos C: Taxonomic status, redescription, and surface ultrastructure of Ascocotyle (Phagicola) pindoramensis $\mathrm{n}$. comb. (Digenea: Heterophyidae). J Parasitolog 2006, 92:501-508.

6. Simões SBE, Neves RFC, Portes Santos C: Life history of Acanthocollaritrema umbilicatum Travassos, Freitas and Bührnheim, 1965 (Digenea: Cryptogonimidae). Parasitol Res 2009, 103:523-528.

7. Simões SBE, Barbosa HS, Portes Santos C: The life history of Pygidiopsis macrostomum Travassos, 1928 (Digenea: Heterophyidae). Mem I Oswaldo Cruz 2009, 104:106-111.

8. Simões SBE, Barbosa HS, Portes Santos C: The life cycle of Ascocotyle (Phagicola) longa (Digenea: Heterophyidae), a causative agent of fishborne trematodosis. Acta Trop 2010, 113:226-33.

9. Santos EGN, Cunha RA, Portes Santos C: Behavioral responses of Poecilia vivipara (Osteichthyies: Cyprinodontiformes) to experimental infections of Acanthocollaritrema umbilicatum (Digenea: Cryptogonimidae). Exp Parasitol 2011, 127:522-526. 
10. Giovanelli A, Silva CLPAC, Leal GBE, Baptista DF: Habitat preference of freshwater molluscs in relation to environmental factors and the presence of the competitor mollusc Melanoides tuberculatus (Müller, 1774). Mem I Oswaldo Cruz 2005, 100:169-176.

11. Pinto HA: Infecção natural de Melanoides tuberculatus (Mollusca: Thiaridae) por Centrocestus formosanus (Trematoda: Heterophyidae) e por Philophthalmus gralli (Trematoda: Philophthalmidae). no Brasil. MSc Dissertation: Universidade Federal de Minas Gerais; 2009 [http://www. bibliotecadigital.ufmg.br/dspace/bitstream/handle/1843/SAGF-8H9QEZ/ disserta_o_hudson_alves_pinto.pdf?sequence=1].

12. Cortés DA, Dolz G, Zúñiga JJR, Rocha AEJ, Alan DL: Centrocestus formosanus (Opisthorchiida: Heterophyidae) como causa de muerte de alevines de tilapia gris Oreochromis niloticus (Perciforme: Cichlidae) en el Pacífico seco de Costa Rica. Rev Biol Trop 2010, 58:1453-1465.

13. Fried B, Graczyk TK, Tamang L: Food-borne intestinal trematodiases in humans. Parasitol Res 2004, 93:159-170.

14. Scholz T, Salgado-Maldonado G: The introduction and dispersal of Centrocestus formosanus (Nishigori, 1924) (Digenea: Heterophyidae) in Mexico: A review. Am Midl Nat 2000, 143:185-200

15. Magalhães DP, Cunha RA, Buss DF, Santos JAA, Baptista DF: Behavioral response of the zebrafish Danio rerio to sublethal stress by sodium hypochlorite-evaluation of a method of toxicological essay by real-time biomonitoring in the laboratory. Ecotoxicology 2007, 16:417-422.

16. R Development Core Team: R: A language and environment for statistical computing. Vienna, Austria: R Foundation for Statistical Computing; 2012. URL http://www.R-project.org/. ISBN 3-900051-07-0.

17. Højsgaard S, Halekoh U, Yan J: The R package geepack for generalized estimating equations. J Stat Softw 2006, 15:1-11.

18. Pan W: Akaike's information criterion in generalized estimating equations. Biometrics 2001, 57:120-125.

19. Probst S, Kube J: Histopathological effects of larval trematode infections in mudmolluscs and their impact on host growth: what causes gigantism in Hydrobia ventrosa (Gastropoda: Prosobranchia)? J Exp Mar Biol Ecol 1999, 238:49-68.

20. Pinheiro J, Maldonado A Jr, Lanfredi RM: Physiological changes in Lymnaea columella (Say, 1817) (Mollusca, Gastropoda) in response to Echinostoma paraensei Lie and Basch, 1967 (Trematoda: Echinostomatidae) infection. Parasitol Res 2009, 10:55-59.

21. Tunholi VM, Lustrino D, Tunholi-Alves VM, Garcia JS, Maldonado A Jr, Rodrigues MLA, Pinheiro J: Influence of Echinostoma paraensei (Lie and Basch, 1967) infection on the calcium content in Biomphalaria glabrata (Say, 1818). Exp Parasitol 2011, 129:266-269.

22. Pinheiro J, Amato SB: Eurytrema coelomaticum (Digenea: Dicrocoelidae): the effect of infection on carbohydrate contents of its intermediate mollusc host, Bradybaena similaris (Gastropoda, Xanthonychidae). Mem I Oswaldo Cruz 1994, 89:407-410.

23. Levri EP, Dillard J, Martin T: Trematode infection correlates with shell shape and defence morphology in a freshwater mollusc. Parasitology 2005, 130:699-708.

24. McCarthy HO, Fitzpatrick SM, Irwin SWB: Parasite alteration of host shape: a quantitative approach to gigantism helps elucidate evolutionary advantages. Parasitology 2004, 128:7-14.

25. Alda P, Bonel N, Cazzaniga NJ, Martorelli SR: Effects of parasitism and environment on shell size of the South American intertidal mud mollusc Heleobia australis (Gastropoda). Est Coast Shelf Sci 2010, 87:305-310.

26. Maure F, Brodeur J, Hughes D, Thomas F: How much energy should manipulative parasites leave to their hosts to ensure altered behavious? J Exp Biol 2013, 216:43-46.

27. Levri EP, Fisher $L$ : The effect of a trematode (Microphallus sp.) on the response of the freshwater mollusc, Potamopyrgus antipodarum to light and gravity. Behaviour 2000, 137:1141-1151.

doi:10.1186/1756-3305-6-92

Cite this article as: dos Santos et al: Does the trematode Centrocestus formosanus affect the locomotory activity of the mollusc Melanoides tuberculatus?. Parasites \& Vectors 2013 6:92.

\section{Submit your next manuscript to BioMed Central and take full advantage of:}

- Convenient online submission

- Thorough peer review

- No space constraints or color figure charges

- Immediate publication on acceptance

- Inclusion in PubMed, CAS, Scopus and Google Scholar

- Research which is freely available for redistribution

Submit your manuscript at www.biomedcentral.com/submit
( BioMed Central 